\title{
Supervisors and teachers' influence on expectations on empowering leadership among students in vocational education and training
}

\author{
Martin Grill ${ }^{1 *} \mathbb{D}$, Anders Pousette ${ }^{1}$, Kent Nielsen²${ }^{2}$, Regine Grytnes ${ }^{2}$ and Marianne Törner ${ }^{1}$
}

*Correspondence:

martin.grill@amm.gu.se

${ }^{1}$ Occupational

and Environmental Medicine,

Department of Public Health and Community Medicine,

Sahlgrenska Academy,

University of Gothenburg,

Box 414, 40530 Gothenburg,

Sweden

Full list of author information is available at the end of the article

\begin{abstract}
Background: Empowering leadership practise among leaders in the construction industry contributes to improve occupational safety, by stimulating participative safety behaviour among construction workers. Socialization into working life in the construction industry begins during vocational education and training (VET). It is therefore important to understand how VET influence young people's expectations on empowering leadership, i.e. their implicit leadership theories (ILT). The aim of the present study was to assess if empowering ILT of students change during VET, and if students' empowering ILT are influenced by the empowering leadership practice of teachers and workplace supervisors that the students interact with during VET.
\end{abstract}

Methods: Questionnaire data were gathered from students $(n=1907)$ at seven construction VET-schools in Sweden and Denmark at two occasions, 1 year apart. Accelerated longitudinal design was employed and data were analysed using mixed method growth curve modelling.

Results: The empowering ILT of the VET-students was found to increase during VET. The leadership of supervisors', but not of teachers', was found to be positively related to the empowering ILT of the VET-students.

Conclusions: VET-students, in the beginning of their professional life, appear to alter their beliefs and assumptions about the characteristics of effective leaders. The ILT of VET-students may thus be regarded as dynamic and responsive, inclined to change as the students socialize into working life.

Keywords: Implicit leadership theory, Empowering leadership, Safety leadership, Construction industry, VET, Socialization, Occupational safety

\section{Background}

\section{Empowering leadership and occupational safety}

Globally, the number of fatal occupational accidents in 2003 were estimated to 360,000 (Hämäläinen et al. 2009). The construction industry is one of the worst affected occupational sectors; among European construction workers $4.8 \%$ reported one or more accidental injuries in 2007 (Eurostat 2010). Traditionally, occupational safety has been managed through physical barriers and implementation of rules and regulations

(c) The Author(s) 2017. This article is distributed under the terms of the Creative Commons Attribution 4.0 International License (http://creativecommons.org/licenses/by/4.0/), which permits unrestricted use, distribution, and reproduction in any medium, provided you give appropriate credit to the original author(s) and the source, provide a link to the Creative Commons license, and indicate if changes were made. 
(Hudson 2007). However, a high level of safety is not only dependent on safety compliant behaviours, but also on participative behaviours, where employees take own initiatives to identify hazards, and improve workplace safety (Neal and Griffin 2006). Safety leadership research indicates the central role of managers and the quality of leadership for the development of participative safety behaviours of employees (Clarke 2013). Empowering leadership is a type of leadership practice that has been found to develop participative safety behaviours among employees (Grill et al. 2015; Shannon et al. 1997; Törner and Pousette 2009). Empowering leadership involves contributing to the psychological empowerment of employees by fostering opportunities for employees to participate in decision-making (Thomas and Velthouse 1990). Psychologically empowered individuals wish and feel able to shape their work role, context and performance (Conger and Kanungo 1988; Spreitzer 1995). Empowering leadership may be defined as "implementing conditions that increase employees' feelings of self-efficacy and control (e.g., participative decision-making), and removing conditions that foster a sense of powerlessness" (Arnold et al. 2000, p. 250). Empowering leadership can be distinguished from other leadership practices as it involves a shift in the source of control from managers to employees, by encouraging participation in decision-making processes (Arnold et al. 2000). Extensive research on empowering leadership describe how such leadership can increase employees' commitment (Hassan et al. 2013), motivation and innovation (Spreitzer 1995; Zhang and Bartol 2010), organizational loyalty (Keller and Dansereaul 1995), team learning (Burke et al. 2006), team performance (Seibert et al. 2011; Srivastava et al. 2006), as well as occupational safety (Grill et al. 2015; Shannon et al. 1997; Törner and Pousette 2009).

\section{The reciprocal process of constructing empowering leadership}

How empowering leadership can be fostered and developed is a concern for practitioners and researchers alike (Labianca et al. 2000; Seibert et al. 2004; Spreitzer 2008; Yukl and Becker 2006; Zhang and Bartol 2010). To understand the complexity of this challenge, the relational and reciprocal character of leadership practice needs to be acknowledged. Effective leadership is inherently relational, performed by managers in close interaction with their employees, and managers are influenced by employees' responses to their leadership (Avolio 2007; Bligh 2011; Gerstner and Day 1997). Thus, both managers and employees contribute to the construction of leadership, and ultimately, to leader effectiveness (Ehrhart 2012; Keller 2003).

Lord and colleagues (Lord et al. 1999; Shondrick et al. 2010), describe leadership as a result of group processes where leadership behaviours are negotiated between managers and employees: "Leadership results from a dynamic and reciprocal interaction between subordinates and superiors that involves leader behaviours, subordinate perceptions, and resulting outcomes" (Lord et al. 1999, p. 197). In this reciprocal interaction, managers and employees' attitudes towards, theories about, and expectations on leadership, appear to play a crucial role for the realization of leadership practice (Lord et al. 1999). Also in the construction of empowering leadership, these reciprocal interactions are essential (Fausing et al. 2015; Grill et al. 2015; Keller and Dansereaul 1995; Labianca et al. 2000). 


\section{Reproducing empowering leadership during vocational education and training}

The collective reciprocal process of leadership construction is part of a vocational socialization process (Buchanan 1974; Nonaka et al. 2006). Socialization begins when an individual start to associate him-or herself with a new working group, an organisation, or work in an industrial sector. The newcomers are subjected to, and gradually internalize, salient social norms, values and customs (Allen and Meyer 1990).

Work, as a potent source of influence on individuals' personalities and values (Heath 1977), may have its most significant socialization effect on a person during the preparation for and initial period of work (Frese 1982). Frese describes socialization as the transmission of systems of norms and social ideas, potent enough to affect individuals' schemas, i.e. the cognitive categorisations of concepts that comprises individuals' understanding of, and knowledge about, the concepts (Frese 1982). Individuals' schemas on leadership are commonly referred to as implicit leadership theories (ILT), and defined as "beliefs and assumptions about the characteristics of effective leaders" (Yukl 2013, p. 233). Lord et al. (1984) describe ILT as building stones that construct an individual's mental schema of leadership, i.e. a cognitive category containing information on what a leader is in terms of traits, abilities and behaviours. The ILT of empowering leadership, or empowering ILT, is the implicit theory that empowering behaviours is a characteristic of effective leaders (cf. Yukl 2013). Social cognitive research has demonstrated how schemas and implicit theories significantly influence judgements, choices, and behaviours (Ayman and Chemers 1983; Engle and Lord 1997; Fiske and Taylor 2013; Greenwald et al. 2009; Hunt et al. 1990; Lord et al. 2001; Nye and Forsyth 1991; Porr and Fields 2006; Rush and Russell 1988; Ajzen 1991).

The socialization into working life in an industrial sector normally begins with industrial specific vocational education and training (VET) (Schaap et al. 2012). During VET, young individuals socialize into professional life by receiving education and training to become working members of a professional community. VET can be understood as a socialization process into working life in general, and into work in a specific industrial sector in particular. During construction industry VET, young individuals socialize into working life in the construction industry, and an essential aspect of this socialization is the transmission of implicit knowledge and understandings (Schaap et al. 2012).

\section{The possible dynamic nature of ILT}

Some ILT are universal and others display notable differences between cultures (Den Hartog et al. 1999; Gerstner and Day 1994; House et al. 2004). Still, the how and when ILT develop is a research area left largely unattended (Foti et al. 2014). Whether ILT are developed during early childhood and stable thereafter, or responsive and dynamic, continuing to develop as individual proceeds into adulthood, is still an unanswered question since only few attempts have been made to assess this. Epitropaki and Martin's (2004) longitudinal study, assessing changes in ILT in an adult population, concluded that ILT are stable mental structures that persist over time and resist change. This conclusion is in line with the general understanding in schema research, that once schemas are formed and established, they tend to endure and be resistant to change, even when disconfirming information is presented (Fiske and Taylor 2013). On the other hand, Dorfman et al. (2004) as well as Shondrick et al. (2010) suggest that ILT develop over time as part of 
normal societal and organizational socialization processes. Empirical research exploring the origin of ILT argues for the significance of childhood and the interaction with the parents, our first leaders, as an important source for the development of individuals' ILT (Keller 2000, 2003; Popper and Amit 2009; Popper et al. 2000).

Individuals who undergo VET commonly do so during late adolescence or early adulthood. To what extent ILT are stable and resistant to change or dynamic and responsive, in adolescence and young adults during VET is unknown. Epitropaki and Martin (2004) call for further research on what happens with individuals' ILT as they first encounter working life, suggesting that socialization into working life may be critical for the development of individuals' ILT. The first aim of the present study was therefore to investigate if the empowering ILT of construction industry VET-students change during the socialization process of becoming a working member of the construction industry, a process that takes place during their time in VET.

Hypothesis 1 The empowering ILT of students changes during VET.

\section{The influence of supervisors and teachers on the ILT of students'}

Rush and Russell (1988) suggest that ILT may be formed and altered when individuals perceive and/or interact with leaders. During VET, young individuals interact extensively with leaders other than their parents. Research on socialization (Allen and Meyer 1990) and social cognition (Bandura and McDonald 1963) suggests that the formation of attitudes and values in young individuals can be strongly affected by such role models. Hence, leaders that the students interact with during VET may potentially be an important source of influence on students' ILT.

VET consists of two separate learning contexts: schools and training companies (Schaap et al. 2012). This divide or boundary (Akkerman and Bakker 2011) constitutes two parallel learning arenas in which VET-students encounter two different types of leaders: teachers at the schools and supervisors at the training companies. Brockman and Laurie (2016) describe how students enrolled in vocational education develop an understanding of themselves as "academic learners" or as "practical learners". The knowledge and understandings of both types of learners where found to be primarily influenced by the practical, vocational aspects of the education, characterised by workplace learning. This indicates that supervisors at the workplace may be the prime role model when it comes to possible changes in the ILT of VET-students. This concord with studies that have identified supervisors at the training companies as a prime source of influence for young individuals learning a trade (Fjellström 2014; Gherardi and Nicolini 2002).

However, the "academic learners" in Brockmann and Laurie's study (2016) also embraced the theoretical parts of the education. This indicates that also teachers may be role models when it comes to possible changes in the ILT of VET-students. In order to further develop VET there is thus a need for studies that elucidate the possible influence of these two types of role models on the ILT of VET-students.

As described by Ford and colleagues (Ford et al. 2014), causal relations can be either synchronous or lagged. Research on social cognition (Fiske and Taylor 2013), suggests that individuals readily categorize themselves as part of a group and that this goal of belonging instantaneously affects people's interpretation of social stimuli. During VET, students may experience contrasts between their ILT and the behaviours of the leaders 
they encounter, and may instantly adjust their ILT according to this new stimulus. Such processes of change suggest that any influence of supervisors and teachers on the ILT of VET-students, would be instantaneous/synchronous. On the other hand, schemas are commonly understood to be stable and resistant to change (Fiske and Taylor 2013). Understanding ILT to be more stable over time suggests that changes would be frictional and that hence any effects of supervisors and teachers' leadership on the ILT of VETstudents would be delayed/lagged. In order to investigate these relations, the following hypotheses were formulated.

Hypothesis 2a Supervisors' empowering leadership has synchronous influence on students' empowering ILT.

Hypothesis 2b Supervisors' empowering leadership has lagged influence on students' empowering ILT.

Hypothesis 3a Teachers' empowering leadership has synchronous influence on students' empowering ILT.

Hypothesis 3b Teachers' empowering leadership has lagged influence on students' empowering ILT.

\section{Methods}

Respondents

Seven construction VET schools were strategically selected to provide variation regarding school size and location in major and minor communities. Since ILT may vary depending on cultural context (House et al. 2004), both Swedish $(\mathrm{n}=4)$ and Danish $(\mathrm{n}=3)$ schools were included, representing two similar countries with divergent VETsystems (Grytnes et al. 2017). The inclusion of both Swedish and Danish VET-students allowed for the assessment of the hypothesised dynamic nature of ILT in two different cultural contexts. All students attending the schools February-June $2014\left(\mathrm{~T}_{1}\right)$ and February-June $2015\left(\mathrm{~T}_{2}\right)$ were invited to participate in the study; the response rate was $80 \%$ at $\mathrm{T}_{1}$ and $83 \%$ at $\mathrm{T}_{2}$. Swedish construction VET is divided into three grades, each of 1-year duration. Danish construction VET comprises up to 4 years. A questionnaire study with accelerated longitudinal design (Duncan et al. 2006) was employed to assess changes in empowering ILT over the whole VET-period using two measure points, one year apart. One year is equivalent to the time lag used in the study by Epitropaki and Martin (2004).

As shown in Table 1, the Swedish respondents $(\mathrm{n}=643$; aged $\mathrm{m}=18.3$ years, $\mathrm{SD}=1.4 ; 94 \%$ male) belonged to four cohorts, defined by how far into VET they had reached. Since the first cohort had not yet started school at $T_{1}$, they were only represented at $\mathrm{T}_{2}$. The second cohort attended first year at $\mathrm{T}_{1}$ and second year at $\mathrm{T}_{2}$. The third cohort attended second year at $T_{1}$ and third year at $T_{2}$. The fourth cohort is only represented at $\mathrm{T}_{1}$ as they had finished school at $\mathrm{T}_{2}$. The Danish respondents $(\mathrm{n}=1264$; aged $\mathrm{m}=22.8$ years, $\mathrm{SD}=3.5 ; 93 \%$ male) belonged to five cohorts. Since the first cohort had not yet started school at $\mathrm{T}_{1}$, they were only represented at $\mathrm{T}_{2}$. The second cohort attended first year at $T_{1}$ and second year at $T_{2}$. The third cohort attended second year at $\mathrm{T}_{1}$ and third year at $\mathrm{T}_{2}$. The fourth cohort attended third year at $\mathrm{T}_{1}$ and fourth year at $\mathrm{T}_{2}$. The firth cohort is only represented at $\mathrm{T}_{1}$ as they had finished school at $\mathrm{T}_{2}$. 
Table 1 Graphical representation of the accelerated time variable

\begin{tabular}{|c|c|c|c|c|c|c|c|c|}
\hline \multicolumn{4}{|c|}{ Swedish VET-students } & \multicolumn{5}{|c|}{ Danish VET-students } \\
\hline & $\begin{array}{l}\text { First } \\
\text { year }\end{array}$ & $\begin{array}{l}\text { Second } \\
\text { year }\end{array}$ & $\begin{array}{l}\text { Third } \\
\text { year }\end{array}$ & & $\begin{array}{l}\text { First } \\
\text { year }\end{array}$ & $\begin{array}{l}\text { Second } \\
\text { year }\end{array}$ & $\begin{array}{l}\text { Third } \\
\text { year }\end{array}$ & $\begin{array}{l}\text { Fourth } \\
\text { year }\end{array}$ \\
\hline $\begin{array}{r}\text { Cohort one } \\
(n=194)\end{array}$ & $\mathrm{T}_{2}$ & & & $\begin{array}{r}\text { Cohort one } \\
(n=286)\end{array}$ & $\mathrm{T}_{2}$ & & & \\
\hline $\begin{array}{r}\text { Cohort two } \\
(n=143)\end{array}$ & $\mathrm{T}_{1}$ & $\mathrm{~T}_{2}$ & & $\begin{array}{r}\text { Cohort two } \\
(n=396)\end{array}$ & $\mathrm{T}_{1}$ & $\mathrm{~T}_{2}$ & & \\
\hline $\begin{array}{l}\text { Cohort } \\
\text { three } \\
(n=149)\end{array}$ & & $\mathrm{T}_{1}$ & $\mathrm{~T}_{2}$ & $\begin{array}{l}\text { Cohort } \\
\text { three } \\
(n=303)\end{array}$ & & $\mathrm{T}_{1}$ & $\mathrm{~T}_{2}$ & \\
\hline \multirow[t]{2}{*}{$\begin{array}{l}\text { Cohort four } \\
(n=157)\end{array}$} & & & $\mathrm{T}_{1}$ & $\begin{array}{r}\text { Cohort four } \\
(n=207)\end{array}$ & & & $\mathrm{T}_{1}$ & $\mathrm{~T}_{2}$ \\
\hline & & & & $\begin{array}{l}\text { Cohort five } \\
\quad(n=72)\end{array}$ & & & & $\mathrm{T}_{1}$ \\
\hline
\end{tabular}

$\mathrm{T}_{1}=2014, \mathrm{~T}_{2}=2015$

\section{Measures}

Implicit leadership theories may reliably be measured using explicit questionnaire items (Hofmann et al. 2005; Wittenbrink et al. 1997). To measure the empowering ILT of the VET-students, the participative decision-making subscale in Arnold et al. (2000) Empowering Leadership Questionnaire (ELQ) was adapted. Only one subscale of the ELQ was used, based on the results from the confirmatory factor analyses in Arnold et al. (2000), which suggest that five-factor models only marginally improves fit to data compared to one-factor models. The participative decision-making subscale was selected, as influence on decision-making may be considered fundamental for empowering leadership practice (Arnold et al. 2000). In addition, this ELQ subscale displayed almost complete overlap with two of the other four subscales in ELQ; factor inter-correlation with coaching was $r=0.91$, and with showing concern, $r=0.91$.

The adaptation and reformulation of the ELQ-items was informed by the formulation of the ILT-items in the global leadership and organizational behaviour effectiveness project (House et al. 2004). The following three items were used to measure students empowering ILT: (1) "An effective leader encourages team members to express ideas and suggestions"; (2) "An effective leader uses team members' suggestions to make decisions"; and (3) "An effective leader considers team members' ideas, even when he/ she disagrees with them". Each item was rated on a six-point Likert-type scale, ranging from completely disagree (1) to completely agree (6). To provide composite scale scores average scores were calculated with each item assigned equal weight (Cronbach's alpha $=0.80)$.

The empowering leadership of school teachers and supervisors at the training companies were measured with two single items on students' experience of each source of leadership. Leaders' listening behaviours is a prerequisite for participative decisionmaking and a core aspect of empowering leadership (Green 2016; Deter and Burris 2007). Hence, items focusing explicitly on teachers and supervisors' listening behaviours were formulated to measure students' experience of teachers and supervisors' empowering leadership: "My teachers at school are keen to listen to suggestions and ideas from us students on how work can be improved" and "My supervisors at the training 
company are keen to listen to suggestions and ideas from us students on how work can be improved". Both items were rated on a frequency scale, from always (1) to never (7). The independent variables were reversely rated to reduce any common method variance (Lindell and Whitney 2001).

\section{Data analysis to assess changes in the empowering ILT of the VET-students}

In accordance with Hertzog and Nesselroade (2003), change was evaluated by employing mixed method growth curve modelling and comparing models with and without fixed and random effects of time. Data were analysed in SPSS version 20. The time variable, time in VET, was computed in accordance with accelerated longitudinal design (Duncan et al. 2006; Table 1). Any changes in the empowering ILT of the students were assumed to be linear. Time was centred at first year of VET.

To assess if the empowering ILT of the students changed, the log likelihood of empty models and models with fixed effects of time were compared. Models were estimated using maximum likelihood (ML), and compared on AIC-values and $\chi^{2}$-tests of the differences in log likelihoods. The fixed effects of time were also estimated with Wald-tests.

To assess if there was any significant difference between individual students in how their empowering ILT changed during VET, random effects of time were introduced to the growth curve models to see if this significantly decreased the log likelihood of the models. Models were estimated using restricted maximum log likelihood (REML), and compared on AIC-values and $\chi^{2}$-tests of the differences in log likelihoods.

\section{Data analysis to assess predictors for the empowering ILT of the VET-students}

The students' experiences of supervisors and teachers' empowering leadership were measured at $T_{1}$ and the students' empowering ILT was measures at $T_{1}$ and $T_{2}$. Instantaneous/synchronous and delayed/lagged influences/effects of each source of leadership on the students' ILT were assessed by employing growth curve modelling and comparing empty models with models that included the students' experiences of each source of leadership as predictors of the students' ILT. In accordance with Ford et al. (2014), single main effects of leadership were estimated to assess the synchronous effects, and interaction effects between leadership and time were estimated to assess the lagged effects. Both predictors were grand mean centred prior to analyses. Models were estimated using maximum log likelihood (ML), and compared on AIC-values and $x^{2}$-tests of the differences in log likelihoods. The fixed effect of time was also estimated with a Waldtest. Only respondents who answered the questionnaire at both measurement points where included in this analysis. To obtain sufficient statistical power for these analyses, respondents from both countries were combined into a single dataset. Possible confounders included in the analyses were gender and country.

\section{Results}

\section{Changes in the empowering ILT of the VET-students}

Considering hypothesis 1 , Tables 2 and 3 provide parameter estimates and standard errors for growth curve models in which individuals' empowering ILT were predicted by 'time' (years) in Swedish and Danish VET respectively. The results are presented in stepwise tests of models with increasing numbers of estimated parameters, starting with 
Table 2 Growth curve models in which empowering ILT is predicted by time in Swedish VET

\begin{tabular}{|c|c|c|c|c|c|c|}
\hline & \multicolumn{2}{|c|}{ Empty model } & \multicolumn{2}{|l|}{ Model 1} & \multicolumn{2}{|l|}{ Model 2} \\
\hline & Par. & S.E. & Par. & S.E. & Par. & S.E. \\
\hline \multicolumn{7}{|l|}{ Fixed effects } \\
\hline Intercept & $5.091^{* *}$ & 0.025 & $5.031^{* *}$ & 0.035 & $5.037^{* *}$ & 0.035 \\
\hline Time & & & $0.063^{* *}$ & 0.026 & $0.065^{* *}$ & 0.027 \\
\hline \multicolumn{7}{|l|}{ Random effects } \\
\hline Residuals & 0.271 & 0.024 & 0.263 & 0.023 & 0.198 & 0.028 \\
\hline Intercept & 0.202 & 0.030 & 0.209 & 0.030 & 0.284 & 0.050 \\
\hline Time & & & & & 0.130 & 0.041 \\
\hline Intercept*time & & & & & -0.117 & 0.042 \\
\hline \multicolumn{7}{|l|}{ Model specifics } \\
\hline Estimation method & $M L$ & & ML/REML & & REML & \\
\hline Log likelihood & 1891.3 & & $1885.4 / 1896.5$ & & 1886.5 & \\
\hline $\mathrm{AIC}$ & 1897.3 & & 1893.4/1900.5 & & 1894.5 & \\
\hline Diff log likelihood (diff df) & & & $5.9 *(1)$ & & $10.0^{* *}(2)$ & \\
\hline
\end{tabular}

$n=643$. Wald tests for fixed effects and $x^{2}$-tests of diff log likelihood for random effects

${ }^{*} p<0.05$

** $\mathrm{p}<0.01$

Table 3 Growth curve models in which empowering ILT is predicted by time in Danish VET

\begin{tabular}{|c|c|c|c|c|c|c|}
\hline & \multicolumn{2}{|c|}{ Empty model } & \multicolumn{2}{|l|}{ Model 1} & \multicolumn{2}{|l|}{ Model 2} \\
\hline & Par. & S.E. & Par. & S.E. & Par. & S.E. \\
\hline \multicolumn{7}{|l|}{ Fixed effects } \\
\hline Intercept & $4.848^{* *}$ & 0.021 & $4.790^{* *}$ & 0.030 & $4.787^{* *}$ & 0.031 \\
\hline Time & & & $0.055^{* *}$ & 0.020 & $0.057^{* *}$ & 0.020 \\
\hline \multicolumn{7}{|l|}{ Random effects } \\
\hline Residuals & 0.462 & 0.047 & 0.457 & 0.047 & 0.434 & 0.047 \\
\hline Intercept & 0.159 & 0.046 & 0.160 & 0.047 & 0.252 & 0.047 \\
\hline Time & & & & & 0.015 & 0.025 \\
\hline Intercept * Time & & & & & -0.047 & 0.034 \\
\hline \multicolumn{7}{|l|}{ Model specifics } \\
\hline Estimation method & $\mathrm{ML}$ & & ML/REML & & REML & \\
\hline Log likelihood & 3346.3 & & $3339.1 / 3350.9$ & & 3344.1 & \\
\hline AIC & 3352.3 & & $3347.1 / 3354.9$ & & 3352.1 & \\
\hline Diff log likelihood (diff df) & & & $7.2^{* *}(1)$ & & $6.8^{*}(2)$ & \\
\hline
\end{tabular}

$\mathrm{n}=1264$. Wald tests for fixed effects and $\mathrm{x}^{2}$-tests of diff log likelihood for random effects

${ }^{*} \mathrm{p}<0.05$

${ }^{* *} p<0.01$

empty models. The level of students' empowering ILT varied between individuals, as indicated by $\mathrm{ICC}_{1}$-values of 0.43 (Sweden) and 0.26 (Denmark).

In Model 1, fixed effects of time were introduced. The empowering ILT of the VETstudents were found to increase as an effect of time in VET, as indicated by significantly lower log likelihoods and significant positive parameter estimates, in both samples. In Model 2, random effects of time were introduced. The increase it the empowering ILT of the VET-students was found to display a significant individual variation, as indicated 


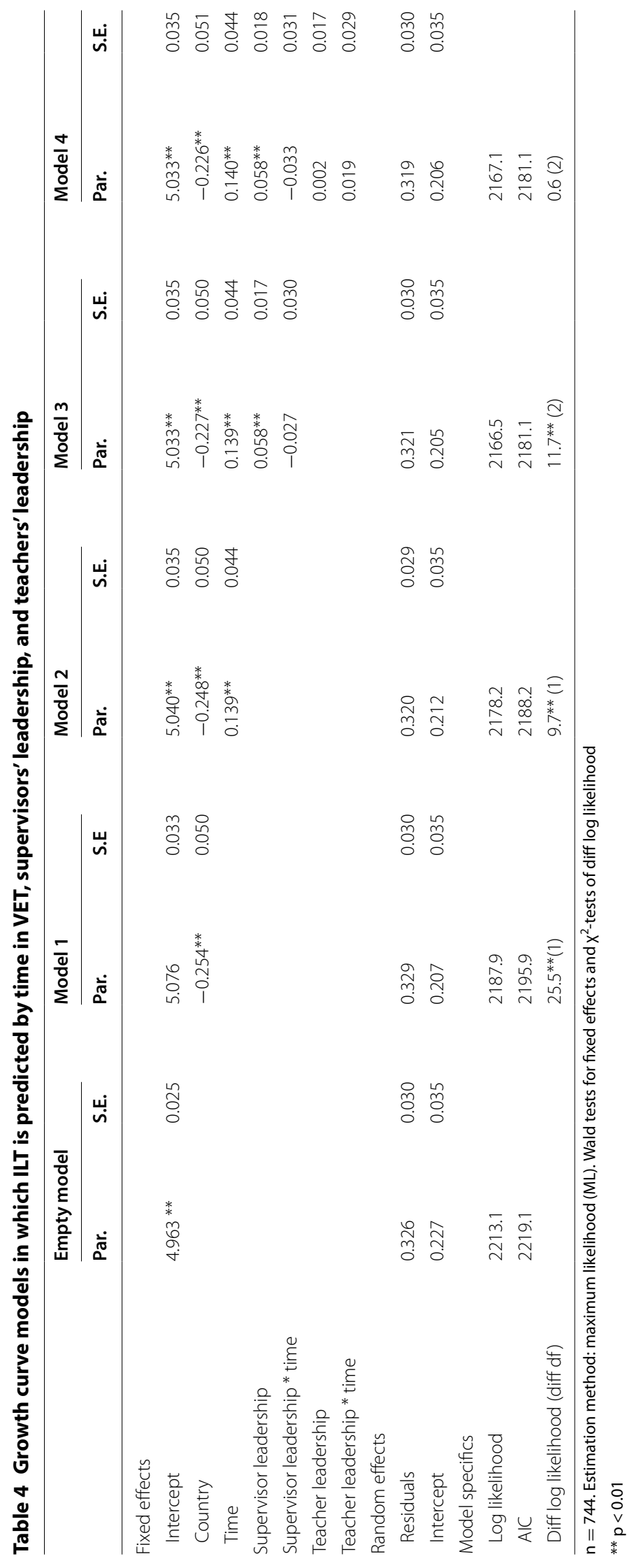


by significantly lower log likelihoods in both samples. Model 2 showed the best fit to data, as indicated by the lowest AIC and log likelihood values, and provide parameter estimates for the fixed effects of time (Sweden: $p=0.017$, Denmark: $p=0.004$ ) as well as the random effects of intercept, time, and the co-variances between intercept and time. The students differed in the level of their empowering ILT when they began VET, as indicated by the random effect of intercept, in both samples. Students that started with a lower level of empowering ILT tended to have a steeper increase in ILT during VET and students that started with a higher level of empowering ILT tended to have less development in ILT, as indicated by the negative co-variances between intercept and time in both samples. Hypothesis 1 was thus supported.

\section{Predictors for the empowering ILT of the VET-students}

Table 4 provides parameter estimates and standard errors for growth curve models, in which the empowering ILT of the VET-students was predicted by 'time' (years) in VET, 'supervisors' leadership', and 'teachers' leadership. The level of empowering ILT varied between individuals $\left(\mathrm{ICC}_{1}=0.41\right)$. In model 1 , 'country' was introduced as a possible confounder. The Swedish VET-students were found to have a higher level of empowering ILT compared to the Danish students, as indicated by a significant positive parameter estimate of the fixed effect of 'country'. In Model 2, 'time' in VET was introduced as a single main effect. The empowering ILT of the VET-students was found to increase as an effect of time spent in VET, as indicated by a significant positive parameter estimate of the fixed effect, confirming the results from the test of hypothesis 1 .

In Model 3, 'supervisors' leadership' was introduced, both as a simple main effect, and as an interaction effect with time. Supervisors' leadership was found to predict students' empowering ILT, as indicated by a significant positive parameter estimate of the simple main effect. However, supervisors' leadership was found not to predict a lagged development in the empowering ILT of the VET-students, as indicated by the lack of any significant interaction effect between supervisors' leadership and time.

In Model 4, 'teachers' leadership' was introduced, both as a simple main effect, and as an interaction effect with time. Teachers' leadership was not found to predict students empowering ILT, as indicated by the lack of any significant parameter estimates.

Model 3 showed the best fit to data and provide parameter estimates for the significant fixed effects of 'country' ( $\mathrm{p}<0.001)$, 'time' in VET $(\mathrm{p}=0.002)$, and 'supervisors' leadership' $(\mathrm{p}=0.001)$.

The results thus indicated that supervisors' leadership had a synchronous, but no lagged, effect on the empowering ILT of the VET-students. Hence, hypothesis 2a was supported, and hypothesis $2 \mathrm{~b}$ was rejected. Teachers' leadership had neither a synchronous nor a lagged effect on students' empowering ILT. Hence, both hypotheses 3a and hypothesis $3 \mathrm{~b}$ were rejected.

\section{Discussion}

The results of this study indicate that during construction VET, the empowering ILT of students is dynamic and changeable. Empowering ILT was found not only to increase in a systematic and directional way; the development also contained significant individual variation. These results thus empirically support a dynamic nature of ILT: VET-students, 
in the beginning of their professional life, appear to alter their beliefs and assumptions about the characteristics of effective leaders.

The co-variance between intercept and time in the growth curve models suggests that the students' leadership schemas convergence during their time in VET. In the course of the common socialisation process into working life in the construction industry that the student undergo during VET, they seem to align their ILT with one another. This interpretation is in line with research in social cognition that describe how perceptions and cognitions typically are affected by the goal of belonging (Fiske and Taylor 2013), and consequently that individuals' cognitive processes (Postmes et al. 2005) and attitudes (Kawakami et al. 2003) converge with those of other individuals within the same group.

Research on behavioural intentions by Ajzen (1991), provides a theoretical framework for understanding how the increase in empowering ILT among the VET-students found in the present study, may well have implications for leadership practices in the construction industry. VET-students, embarking on leadership positions and becoming supervisors, team leaders, and managers, can influence the leadership in the construction industry to become more participative by conveying their empowering ILT in manifest leadership behaviours (cf. attitude toward behaviour, in Ajzen 1991), as well as conforming to the empowering ILT of colleagues, superiors, and subordinates (cf. subjective norm, in Ajzen 1991). In addition, leadership is inherently relational, performed by managers in close interaction with their employees (Gerstner and Day 1997; Avolio 2007; Bligh 2011), VET-students, qua future construction workers, may consequently also influence leadership pracise in the construction industry to become more participative, by expressing their expectations on the leadership of supervisors, team leaders, and managers (cf. subjective norm, in Ajzen 1991). During construction VET, the future construction managers and workers socialize into the leadership practices of the construction industry, and as they become working members of the industry they may well participate themselves in the reproduction of empowering leadership practice, by conveying their empowering ILT in manifest behaviours. Hence, the increase in the empowering ILT of the VET-students found in the present study, aligned with previous research on the processes behind leadership construction, suggests that the participative leadership culture in the construction industry (Grill et al. 2015) may be reproduced during construction VET.

The results indicated that the leadership of supervisors, but not of teachers', is positively related to the empowering ILT of the VET-students. This is in line with previous research underlining supervisors as central role models for students. The goal of belonging is a driving force in perception and mental representation (Fiske and Taylor 2013), and since VET is intended to prepare students for professional work and not for further studies, the students' goal of belonging may be more directed toward a future work context, where supervisors at the training companies are prime role models for leadership, than toward an educational context, where teachers at the schools are prime role models for leadership.

However, the study revealed no lagged effect of supervisors' leadership on students' ILT from one year to the next. Here it should be noted that the students often changed their training company during VET, with corresponding changes in supervisors. These changes may have obscured the influence over time of discrete supervisors, as changes 
in training company were not accounted for in the study design. The results of this study thus provide a starting point for more fine-grained investigations of the influence of supervisors' leadership on the development in students' ILT during VET. It also raises research questions on how the teachers' role may be developed to further reinforce a positive influence of VET on the development of students' ILT. Answers to such questions may be of large practical importance to organizers of VET-programs.

The changes in the empowering ILT of the VET-students were found to be similar in Sweden and Denmark. However, country did emerge as a significant predictor for the level of empowering ILT. This finding indicates that empowering leadership may be more highly valued in the Swedish construction industry than in the Danish ditto. This result concord with previous research indicating that participative leadership is more prevalent in Sweden than in Denmark (Grill et al. 2015; Holmberg and Åkerblom 2007; Isaksson 2008; Schramm-Nielsen et al. 2004). The difference between countries in empowering ILT already at the start of VET, found in the present study, also indicates cultural differences in ILT, which develop also during childhood.

\section{Limitations}

There is an abundance of cross-sectional leadership research aiming at addressing the subject of change (Hunter et al. 2007). Longitudinal research is generally called for. However, longitudinal study designs are both time and money consuming. The accelerated longitudinal design, employed in this study, demands less resource and demonstrates that long-term changes may be studied in shorter time periods. However, an accelerated design with only two measurement points assumes change to be linear. To test this assumption, more than the two measurement points available in this study, are necessary.

Using the same method to collect data on dependent and independent variables involves a risk that results may be influenced by common method bias. However, the results indicated that the influence of leadership on the ILT of the VET-students was attributable only to supervisors', and not to teachers' leadership. If the relation found were due to common method bias, similar relational patterns would have been expected for both categories.

Since the empirical base for this study was empowering ILT among adolescents and young adults in construction VET, the results should not hastily be generalized to other ILT, other periods in the life span of individuals, or to other industrial sectors. Replication of this study with an extended number of ILT is called for to assess how different ILT change in different contexts and in different age groups.

\section{Conclusions}

By providing an example of a time bound change in empowering ILT, this study contributes to our understanding of implicit leadership theories. The findings support a theoretical standpoint suggesting that ILT may be regarded as dynamic and responsive mental structures, inclined to change if the psychosocial context of the individual changes sufficiently, at least still during early adulthood.

The empowering ILT of the VET-students were found to be more related to the students' experiences of the leadership behaviours of supervisors that they encounter at the 
training companies, than the leadership they experience from teachers at the schools. Supervisors at the training companies seem to be important role models of leadership for VET-students. It may benefit VET-supervisors to be aware of, and appreciate their importance as such transmitters of leadership to young individuals learning the trade.

During construction VET, the future construction managers and workers socialize into the leadership practices of the construction industry, and as they become working members of the industry they may well participate themselves in the reproduction of empowering leadership practice, by conveying their empowering ILT in manifest behaviours.

\section{Authors' contributions}

All authors have contributed substantially in the design, data collection and writing of this publication. Data analyses were conducted by MG and AP. All authors read and approved the final manuscript.

\section{Author details}

1 Occupational and Environmental Medicine, Department of Public Health and Community Medicine, Sahlgrenska Academy, University of Gothenburg, Box 414, 40530 Gothenburg, Sweden. ${ }^{2}$ Department of Occupational Medicine, Regional Hospital West Jutland-University Research Clinic and Danish Ramazzini Centre, Herning, Denmark.

\section{Acknowledgements}

Not applicable.

\section{Competing interests}

The authors declare that they have no competing interests.

\section{Availability of data and materials}

Data and materials described in the manuscript are available by contacting the main author of the article (martin.grill@ amm.gu.se).

\section{Consent to participate}

All research subjects consented to participate in the research.

\section{Consent for publication}

All participants were given full anonymity; no data relating to individual participants are included in the paper.

\section{Ethics approval}

Ethics approval, number 547-14, was obtained from the Regional Ethics Committee in Gothenburg.

\section{Funding}

This work was part of the SveDan project, funded by the Danish Working Environment Research Fund under Grant Number 01-2012-09; the Health Research Fund of Central Denmark Region; and AFA Insurance under Grant Number 120176. None of the funding bodies participated in any part of the research.

Received: 28 June 2016 Accepted: 24 January 2017

Published online: 02 February 2017

\section{References}

Ajzen I (1991) The theory of planned behavior. Organ Behav Hum Decis Process 50:179-211

Akkerman SF, Bakker A (2011) Boundary crossing and boundary objects. Rev Educ Res 81:132-169

Allen NJ, Meyer JP (1990) Organizational socialization tactics: a longitudinal analysis of links to newcomers' commitment and role orientation. Adec Manag J 33:847-858

Arnold JA, Arad S, Rhoades JA, Drasgow F (2000) The empowering leadership questionnaire: the construction and validation of a new scale for measuring leader behaviors. J Organ Behav 21:249-269

Avolio BJ (2007) Promoting more integrative strategies for leadership theory-building. Am Psychol 62:25-33

Ayman R, Chemers MM (1983) Relationship of supervisory behavior ratings to work group effectiveness and subordinate satisfaction among Iranian managers. J Appl Psychol 68:338-341

Bandura A, McDonald FJ (1963) Influence of social reinforcement and the behavior of models in shaping children's moral judgment. J Abnorm Soc Psychol 67:274-281

Bligh MC (2011) Followership and follower-centered approaches. In: Collinson D, Grint K, Jackson B, Uhl-Bien M (eds) Bryman A. Sage Publications, The SAGE handbook of leadership

Brockmann M, Laurie I (2016) Apprenticeship in England-the continued role of the academic-vocational divide in shaping learner identities. J Vocat Educ Train. doi:10.1080/13636820.2016.1143866

Buchanan B (1974) Building organizational commitment: the socialization of managers in work organizations. Admin Sci Quart 19:533-546

Burke CS, Stagl KC, Klein C, Goodwin GF, Salas E, Halpin SM (2006) What type of leadership behaviors are functional in teams? A meta-analysis. Leadersh Q 17:288-307

Clarke S (2013) Safety leadership: a meta-analytic review of transformational and transactional leadership styles as antecedents of safety behaviours. J Occup Organ Psych 86:22-49 
Conger JA, Kanungo RN (1988) The empowerment process: integrating theory and practice. Acad Manag Rev 13:471-482

Den Hartog DN, House RJ, Hanges PJ, Ruiz-Quintanilla SA, Dorfman PW (1999) Culture specific and cross-culturally generalizable implicit leadership theories: are attributes of charismatic/transformational leadership universally endorsed? Leadersh Q 10:219-256

Deter JR, Burris ER (2007) Leadership behavior and employee voice: is the door really open? Acad Manag J 50:869-884

Dorfman PW, Hanges PJ, Brodbeck FC (2004) Leadership and cultural variation: the identification of culturally endorsed leadership profiles. In: House RJ, Hanges PJ, Javidan M, Dorfman PW, Gupta V (eds) Culture, leadership, and organizations: the GLOBE Study of 62 Societies. Sage Publications, Thousand Oaks

Duncan TE, Duncan SC, Strycker LA (2006) An introduction to latent variable growth curve modeling: Concepts, issues, and application, 2nd edn. Lawrence Erlbaum Associates, London

Ehrhart MG (2012) Self-concept, implicit leadership theories, and follower preferences for leadership. Z Psychol 220:231-240

Engle EM, Lord RG (1997) Implicit theories, self-schemas, and leader-member exchange. Acad Manag J 40:988-1010

Epitropaki O, Martin R (2004) Implicit leadership theories in applied settings: factor structure, generalizability, and stability over time. J Appl Psychol 89:293-310

Eurostat (2010) Health and safety at work in Europe (1999-2007) - a statistical portrait. European Commission Employment, Social Affairs and Equal Opportunities. European Union, City of Brussels

Fausing MS, Joensson TS, Lewandowski J, Bligh M (2015) Antecedents of shared leadership: empowering leadership and interdependence. Leader Organ Dev J 36:271-291

Fiske ST, Taylor SE (2013) Social cognition: from brains to culture, 2nd end. Sage, London

Fjellström M (2014) Vocational education in practice: a study of work-based learning in a construction programme at a Swedish upper secondary school. Empir Res Voc Ed Train 6:1-20

Ford MT, Matthews RA, Wooldridge JD, Mishra V, Kakar UM, Strahan SR (2014) How do occupational stressor-strain effects vary with time? A review and meta-analysis of the relevance of time lags in longitudinal studies. Work Stress 28:9-30

Foti R, Hansbrough TK, Epitropaki O, Coyle P (2014) Special issue: dynamic viewpoints on implicit leadership and followership theories. Leadersh Q 25:411-412

Frese M (1982) Occupational socialization and psychological development: an underemphasized research perspective in industrial psychology. J Occup Organ Psych 55:209-224

Gerstner CR, Day DV (1994) Cross-cultural comparison of leadership prototypes. Leadersh Q 5:121-134

Gerstner CR, Day DV (1997) Meta-Analytic review of leader-member exchange theory: correlates and construct issues. J Appl Psychol 82:827-844

Gherardi S, Nicolini D (2002) Learning the trade: a culture of safety in practice. Organization 9:191-223

Green J (2016) Listening as leadership. Schools Stud Educ 13:211-222

Greenwald AG, Poehlman TA, UhImann EL, Banaji MR (2009) Understanding and using the implicit association test: III. Meta-analysis of predictive validity. J Pers Soc Psychol 97:17-41

Grill M, Grytnes R, Törner M (2015) Approaching safety in the Swedish and Danish construction industry: Professionals' perceptions of safety culture differences. Saf Sci Mon 19:1-17

Grytnes R, Grill M, Pousette A, Törner M, Nielsen KJ (2017) Apprentice or student? The structures of construction industry vocational education and training in Denmark and Sweden and their possible consequences for safety learning. Vocat Learn (in press)

Hämäläinen P, Leena Saarela K, Takala J (2009) Global trend according to estimated number of occupational accidents and fatal work-related diseases at region and country level. J Saf Res 40:125-139

Hassan S, Mahsud R, Yukl G, Prussia GE (2013) Ethical and empowering leadership and leader effectiveness. J Manag Psychol 28:133-146

Heath DH (1977) Some possible effects of occupation on the maturing of professional men. J Vocat Behav 11:263-281

Hertzog C, Nesselroade JR (2003) Assessing psychological change in adulthood: an overview of methodological issues. Psychol Aging 18:639-657

Hofmann W, Gawronski B, Gschwendner T, Le H, Schmitt M (2005) A meta-analysis on the correlation between the implicit association test and explicit self-report measures. Pers Soc Psychol Bull 31:1369-1385

Holmberg I, Åkerblom S (2007) "Primus inter pares" Leadership and Culture in Sweden. In: Chhokar JS, Brodbeck FC, House RJ (eds) Culture and leadership across the world: the GLOBE book of in-depth studies of 25 Societies. Routledge, New York

House RJ, Hanges PJ, Javidan M, Dorfman PW, Gupta V (2004) Culture, leadership, and organizations: The GLOBE study of 62 societies. Sage Publications, Thousand Oaks

Hudson P (2007) Implementing a safety culture in a major multi-national. Saf Sci 45:697-722

Hunt J, Boal KB, Sorenson RL (1990) Top management leadership: inside the black box. Leadersh Q 1:41-65

Hunter ST, Bedell-Avers KE, Mumford MD (2007) The typical leadership study: assumptions, implications, and potential remedies. Leadersh Q 18:435-446

Isaksson P (2008) Leading companies in a global age-managing the Swedish way. Vinnova Rep VR 2008:14

Kawakami K, Dovidio JF, Dijksterhuis A (2003) Effect of social category priming on personal attitudes. Psychol Sci 14:315-319

Keller T (2000) Images of the familiar: individual differences and implicit leadership theories. Leadersh Q 10:589-607

Keller T (2003) Parental images as a guide to leadership sensemaking: an attachment perspective on implicit leadership theories. Leadersh Q 14:141-160

Keller T, Dansereaul F (1995) Leadership and empowerment: a social exchange perspective. Hum Relat 48:127-146

Labianca G, Gray B, Brass DJ (2000) A grounded model of organizational schema change during empowerment. Organ Sci 11:235-257

Lindell MK, Whitney DJ (2001) Accounting for common method variance in cross-sectional research designs. J Appl Psychol 86:114-121 
Lord RG, Foti RJ, De Vader CL (1984) A test of leadership categorization theory: internal structure, information processing, and leadership perceptions. Organ Behav Hum Perform 34:343-378

Lord RG, Brown DJ, Freiberg SJ (1999) Understanding the dynamics of leadership: the role of follower self-concepts in the leader/follower relationship. Organ Behav Hum Decis Process 78:167-203

Lord RG, Brown DJ, Harvey JL, Hall RJ (2001) Contextual constraints on prototype generation and their multilevel consequences for leadership perceptions. Leadersh Q 12:311-338

Neal A, Griffin MA (2006) A study of the lagged relationships among safety climate, safety motivation, safety behavior, and accidents at the individual and group levels. J Appl Psychol 91:946-953

Nonaka I, Von Krogh G, Voelpel S (2006) Organizational knowledge creation theory: evolutionary paths and future advances. Organ Stud 27:1179-1208

Nye JL, Forsyth DR (1991) The effects of prototype-based biases on leadership appraisals. A test of leadership categorization theory. Small Group Res 22:360-379

Popper M, Amit K (2009) Attachment and leader's development via experiences. Leadersh Q 20:749-763

Popper M, Mayseless O, Castelnovo O (2000) Transformational leadership and attachment. Leadersh Q 11:267-289

Porr D, Fields D (2006) Implicit leadership effects on multi-source ratings for management development. J Manag Psychol 21:651-668

Postmes T, Haslam SA, Swaab RI (2005) Social influence in small groups: an interactive model of social identity formation. Eur Rev Soc Psychol 16:1-42

Rush MC, Russell JE (1988) Leader prototypes and prototype-contingent consensus in leader behavior descriptions. J Exp Soc Psychol 24:88-104

Schaap H, Baartman L, De Bruijn E (2012) Students'learning processes during school-based learning and workplace learning in vocational education: a review. Vocat Learn 5:99-117

Schramm-Nielsen J, Lawrence P, Sivesind KH (2004) Management in Scandinavia. Edward Elgar, Cheltenham

Seibert SE, Silver SR, Randolph WA (2004) Taking empowerment to the next level: a multiple-level model of empowerment, performance, and satisfaction. Acad Manag J 47:332-349

Seibert SE, Wang G, Courtright SH (2011) Antecedents and consequences of psychological and team empowerment in organizations: a meta-analytic review. J Appl Psychol 96:981-1003

Shannon HS, Mayr J, Haines T (1997) Overview of the relationship between organizational and workplace factors and injury rates. Saf Sci 26:201-217

Shondrick SJ, Dinh JE, Lord RG (2010) Developments in implicit leadership theory and cognitive science: applications to improving measurement and understanding alternatives to hierarchical leadership. Leadersh Q 21:959-978

Spreitzer GM (1995) Psychological empowerment in the workplace: dimensions, measurement, and validation. Acad Manag J 38:1442-1465

Spreitzer GM (2008) Taking stock: a review of more than twenty years of research on empowerment at work. In: Barling J, Cooper CL (eds) The SAGE handbook of organizational behavior Volume one: micro approaches. Sage Publications, Thousand Oaks

Srivastava A, Bartol KM, Locke EA (2006) Empowering leadership in management teams: effects on knowledge sharing, efficacy, and performance. Acad Manag J 49:1239-1251

Thomas KW, Velthouse BA (1990) Cognitive elements of empowerment: an "interpretive" model of intrinsic task motivation. Acad Manag Rev 15:666-681

Törner M, Pousette A (2009) Safety in construction-a comprehensive description of the characteristics of high safety standards in construction work, from the combined perspective of supervisors and experienced workers. I Saf Res 40:399-409

Wittenbrink B, Judd CM, Park B (1997) Evidence for racial prejudice at the implicit level and its relationship with questionnaire measures. J Pers Soc Psychol 72:262-274

Yukl GA (2013) Leadership in organizations, 8th edn. Pearson Education, Edinburgh Gate

Yukl GA, Becker WS (2006) Effective empowerment in organizations. Org Manag J 3:210-231

Zhang X, Bartol KM (2010) Linking empowering leadership and employee creativity: the influence of psychological empowerment, intrinsic motivation, and creative process engagement. Acad Manag J 53:107-128

\section{Submit your manuscript to a SpringerOpen ${ }^{\circ}$ journal and benefit from:}

- Convenient online submission

- Rigorous peer review

Immediate publication on acceptance

- Open access: articles freely available online

- High visibility within the field

- Retaining the copyright to your article

Submit your next manuscript at $\boldsymbol{\nabla}$ springeropen.com 